Original Article

\title{
KAP study of solid waste disposal of households in Kuttar \& Manjanadi Panchayath covered under gramaskhema programme of K.S. Hegde Medical Academy
}

\author{
K.G. Kiran ${ }^{1}$, Sanjay Kini', Ravi K. ${ }^{3}$, Santhosh N.P. ${ }^{3}$ \& N. Udaya Kiran ${ }^{4}$ \\ ${ }^{1}$ Associate Professor, ${ }^{2}$ Assistant Professor, ${ }^{3}$ M edico-Social Worker, ${ }^{4}$ Professor \& HOD \\ Department of Community Medicine, K.S. Hegde M edical Academy, Nitte University, M angalore, Karnataka, India. \\ Correspondence \\ K.G. Kiran \\ Associate Professor, Department of Community M edicine, K.S. Hegde M edical Academy, \\ Nitte University, Mangalore 575018, Karnataka, India. \\ E-mail : kgkirankg@gmail.com
}

\begin{abstract}
An important problem faced by many societies across the world is unhealthy disposal of solid wastes. Knowledge, attitude, practices of people plays a crucial role as their view point is extremely vital in providing solutions to future environmental problems. A cross sectional study was conducted among the households of Kuttar and M anjanadi villages and a sample of 120 households were studied. M ajority had a good knowledge about the ill effects of improper solid waste disposal and that $82.5 \%$ said collectively that it causes disease, unpleasant odour, unpleasant site and rodent nuisance. M ajority of them had a positive attitude towards solid waste disposal and $98.3 \%$ felt that improper solid waste removal and disposal effects environment. Regarding household waste disposal practice it was found to be unsatisfactory as 78 households disposed of household wastes by just throwing away outside the house. Strict surveillance, supervision and timely removal for disposal of solid waste by management are the key factors in reducing environmental hazards.
\end{abstract}

Key words-Solid waste management, knowledge, attitude, practice

\section{Introduction}

Solid waste is the unwanted or useless solid materials generated from combined residential, industrial and commercial activities in a given area. It may be categorised according to its origin (domestic, industrial, commercial, construction or institutional); according to its contents (organic material, glass, metal, plastic paper etc); or according to hazard potential (toxic, non-toxin, flammable, radioactive, infectious etc) ${ }^{1}$. M anagement of solid waste reduces or eliminates adverse impacts on the environment and human health and supports economic development and improved quality of life. A number of processes are involved in effectively managing waste for a municipality.

\begin{tabular}{|c|}
\hline Access this article online \\
\hline Quick Response Code \\
\hline
\end{tabular}

These include monitoring, collection, transport, processing, recycling and disposal'. Methods of waste reduction, waste reuse and recycling are the preferred options when managing waste. Other methods of waste reduction includes manufacturing products with less packaging, encouraging customers to bring their own reusable bags for packaging, encouraging the public to choose reusable products such as cloth napkins andreusable plastic and glass containers, backyard composting and sharing and donating any unwanted items rather than discarding them. There are many environmental benefits that can be derived from the use of these methods. They reduce or prevent green house gas emissions, reduce the release of pollutants, conserve resources, save energy and reduce the demand for waste treatment technology and landfill space ${ }^{3}$. Therefore it is advisable that these methods be adopted and incorporated as part of the waste management plan.

With rising urbanization and change in lifestyle and food habits, the amount of municipal solid waste has been increasing rapidly and its composition changing. In 1947 cities and towns in India generated an estimated 6 million tonnes of solid waste; in 1997 it was about 48 milliontonnes ${ }^{4}$. More than $25 \%$ of the municipal solid 
waste is not collected at all; $70 \%$ of the Indian cities lack adequate capacity to transport it and there are no sanitary landfills to dispose of the waste 4 . The existing landfills are neither well equipped nor well managed and are not lined properly to protect against contamination of soil and ground water. With increase in the global population and the rising demand for food and other essentials, there has been a rise in the amount of waste being generated daily by each household. This waste is ultimately thrown into municipal waste collection centres from where it is collected by the area municipalities to be further thrown into the landfills and dumps. However, either due to resource crunch or inefficient infrastructure, not all of this waste gets collected and transported to the final dump sites. If at this stage the management and disposal is improperly done, it can cause serious impacts on health and problems to the surrounding environment. The group at risk from the unscientific disposal of solid waste include the population in areas where there is no proper waste disposal method, especially the pre-school children; waste workers; and workers in facilities producing toxic and infectious material. Other high-risk group includes population living close to a waste dump and those, whose water supply has become contaminated either due to waste dumping or leakage from landfill sites. Uncollected solid waste also increases risk of injury, and infection ${ }^{5}$. With increasing use of packing materials, disposables \&polythene bags management of solid waste disposal is a major problem in both rural $\&$ urban areas, specially so in cities with lack of infrastructure. This study was basically undertaken to assess the Knowledge, Attitude \& Practice of solid waste collection $\&$ disposal amongst the households of Kuttar \& M anjanadi Panchayath, which come under the field practice area of K.S. Hegde Medical Academy, Mangalore, which can play an important role in management of solid waste in a town/municipality or a Panchayath.

\section{Methodology}

The KAP study was a cross sectional study in which the Head of the households were interviewed on a pre-tested questionnaire by the trained field staff. The study was carried out from 01 Aug 201431 Dec 2014.The place of study was Kuttar \& Manjanadi Panchayath in Mangalore, Dakshina Kannada dist. The study includes households that have been dwelling in the respective place at least 6 months prior to the time of interview. A total of - 120 households were covered during the study. Universal sampling technique was followed in which all the households which were covered by the Gramakshema scheme of K.S. Hegde M edical Academy was covered during the study. Both quantitative and qualitative data was collected in this study. A structured questionnaire was administered to the households on their knowledge, attitude, and practices in solid waste disposal after obtaining their informed consent. It had parts that are multiple choice questions and others that are open ended to allow the households to express their attitude and perception of specific areas within the services by the local body. Data was analysed using SPSS version 16. Categorical data was expressed as percentages and proportions.

\section{Results}

There were total of 120 households. Socio-demographic variables are depicted in table 1 . Thirty two households (26.7\%) had a total of less than 5 family members, 81 (67.5\%) had 5-10 family members and 7 (5.8\%) had more than 10 family members. It was found that $82(65.3 \%)$ households had a puccahouse and 38 (31.7\%) had a kutcha house. According to modified BG Prasad classification (2014) majority, about 107 (89.2\%) families belonged to class V socio-economic strata. About $10(8.3 \%)$ belonged to class IV socio-economic strata, 2 (1.7\%) families belonged to class III socio-economic strata and $1(0.8 \%)$ belonged to class II Socio-economic strata. When we assessed the knowledge of the participants about what is solid waste, 60 participants said that it is unwanted materials left over from human activity, 51 participants said that it is something hazardous to human health, 76 participants said that it is a source of recyclable materials, 102 participants said it is rotten / spoilt food and 70 participants said that it is broken items that cannot be repaired. When asked who is responsible for removal of household waste to waste collection dump, 35 (29.2\%) householdssaid that it's the house occupants, 20 (16.7\%) said that it's the local 
governing body and $65(54.2 \%)$ said that it's both. When asked what happens if solid waste is not disposed in time,10 (8.3\%) households said that it causes disease, 11 $(9.2 \%)$ said that it causes unpleasant site and 99 (82.5\%) said collectively that it causes disease, unpleasant odour, unpleasant site and rodent nuisance. Knowledge of the subjects regarding disposal, segregation and recycling of solid wastes is shown in Table 2. Fig 1 depicts the response of the households regarding the knowledge as to how often kitchen wastes and general solid wastes need to be removed from the house When the respondents were asked as to why is it important to remove solid wastes regularly from the house, 50 (41.6\%) of them said that it is unhygienic, $6(5.0 \%)$ said that it is to avoid bad smell, 8 (6.6\%) said that because otherwise it will attract rats and insects and 56 (46.6\%)said that it is all of the above facts. When asked what are the different methods by which wastes can be disposed of, 72 said that it's by burning, 5 said that it's by dumping in municipality pit/bin and 43collectively said that it's by burning, burying in a pit, throwingin pits or low lyingareas and dumping in municipality pit/bin.Neighbours 20(16.7\%), friends $15(12.5 \%)$, newspapers 15 (12.5\%) were the major source of information about solid waste management to the households, rest got information from other sources. The attitude of the participants regarding disposal of solid wastes is shown in table 3. When we accessed the practices of households regarding solid waste disposal we found that $92(76.6 \%)$ households generated less than or equal to one $\mathrm{kg}$ of solid wastes per day whereas 28 (23.4\%) households generated $1-2 \mathrm{~kg}$ of solid wastes per day. Regarding waste removal practice it was found thatabout 100 (83.3\%) households removed solid wastes once a day from their house, $14(11.6 \%)$ of them removed twice a day and 6 (5.1\%) of them removed it once in 2 days. When asked what is the distance of the govt/ panchayat waste dumping area from the house, 20 (16.6\%) of them said its less than 500 meters, $68(56.6 \%)$ of them said its more than 500 meters, $32(26.6 \%)$ of them said its more than $1 \mathrm{~km}$. Figure 2 shows the various methods of disposal practiced by different households. When asked how often the waste is removed from waste collecting/dumping area 26 (21.6\%) said its daily, 6 (5.0\%) said its once in 2 weeks and $88(73.4 \%)$ said never. It was observed that only 16 (13.3\%) knew that who removes waste from dumping area. Out of that, $10(8.3 \%)$ said that its gram panchayath and $6(5.0 \%)$ said that its municipality. Regarding waste segregation practices $39(32.5 \%)$ households said that they segregate wastes before disposal and 104 (86.6\%) used to compost kitchen and garden wastes at home. Regarding storage of solid waste, $104(86.6 \%)$ used to store wastes in closed containers and 10 (8.3\%) used to store in polythene bags before disposal. The methods of wastedisposal bythe households are shown in Table 4

Regarding attitude towards reducing household wastes 119 (99.1\%) said that they want to reduce household wastes. Regarding the content of household waste 115 said that their household wastes contain mostly vegetable matter, 120 said that it contains plastic, 5 said it contains polythene and 115 said it contains paper. When assessed for the methods by which they intend to reduce household wastes 61 said that they intend to reduce household wastes by buying only required items, 59 said by buying less of plastic goods, 39 said by carrying own bags to market so as to reduce buying plastic bags. $113(94.1 \%)$ said that they do use reusable items. Out of those who use 31 said it is because it reduces household wastes, 30 said that it reduces household expenditure and 52 said that it is good for the environment. Regarding removal of waste from the house,10 (8.3\%) households said that father removes wastes from house to dumping area/pit, 56 (46.6\%) said mother removes and $54(45.1 \%)$ said all of them remove by turns. Figure 3 shows the area of dumping household wastes by the study subjects

When asked why do they dump household wastes in street and not in dumping areas, 82 households said that no proper dumping area is present, 25 said dumping area is far from house and 28 said it's convenient. 103 (85.8\%) said that the local government is not taking action on this and the rest said they have no idea. Only 6 of them said waste removal and Management in their area is satisfactory and the rest said it's unsatisfactory. Regarding the reason for unsatisfactory management of waste, 82 of them quoted the absence of waste collection and removal management, 
45 said that it's lack of demarcated area or dustbin provided for dumping waste, 68 said waste is not removed in time.

Table 1: Socio-demographic variables

\begin{tabular}{|l|l|l|l|}
\hline Occupation & Number (\%) & Lteracy of Head & Number (\%) \\
\hline of Head & & & \\
\hline Skilled & $24(20.0)$ & Illiterate & $26(21.7)$ \\
\hline Unskilled & $51(42.5)$ & Primary school & $78(65.0)$ \\
\hline Housewife & $14(11.7)$ & Secondary school & $15(12.5)$ \\
\hline Retired & $31(25.8)$ & Graduation & $1(0.8)$ \\
\hline Total & $120(100.0)$ & Total & $120(100.0)$ \\
\hline
\end{tabular}

Table 2: Knowledge regarding disposal, segregation and recycling of solid wastes

\begin{tabular}{|l|c|c|}
\hline Question & Answer & Number (\%) \\
\hline $\begin{array}{l}\text { Does improper solid waste removal } \\
\text { \& disposal effect Environment? }\end{array}$ & Yes & $118(98.3)$ \\
\hline $\begin{array}{l}\text { Do you have an idea of } \\
\text { waste segregation? }\end{array}$ & Yes & $42(35.0)$ \\
\hline $\begin{array}{l}\text { Do you know about recycling } \\
\text { of waste? }\end{array}$ & Yes & $35(29.2)$ \\
\hline $\begin{array}{l}\text { Does production of more waste } \\
\text { harm the environment? }\end{array}$ & Yes & $99(82.5)$ \\
\hline
\end{tabular}

Table 3: The attitude of the participants regarding disposal of solid wastes

\begin{tabular}{|c|c|c|}
\hline Question & Answer & Number (\%) \\
\hline $\begin{array}{l}\text { Do you feel that street should be } \\
\text { clean \& be free of solid waste? }\end{array}$ & Yes & $114(95.0)$ \\
\hline $\begin{array}{l}\text { Are you concerned about disposal } \\
\text { of house hold solid waste? }\end{array}$ & Yes & $120(100.0)$ \\
\hline $\begin{array}{l}\text { Are you \& your house hold members } \\
\text { willing to carry house hold waste to } \\
\text { collecting point? }\end{array}$ & Yes & $120(100.0)$ \\
\hline $\begin{array}{l}\text { Do you play an important role in solid } \\
\text { waste disposal? }\end{array}$ & Yes & $109(90.8)$ \\
\hline $\begin{array}{l}\text { Does the community play an } \\
\text { important role in solid waste disposal? }\end{array}$ & Yes & $77(64.1)$ \\
\hline role in solid waste disposal? & Yes & $77(64.1)$ \\
\hline $\begin{array}{l}\text { Should solid waste disposal be taught } \\
\text { in school as part of Environmental } \\
\text { education? }\end{array}$ & Yes & $119(99.1)$ \\
\hline $\begin{array}{l}\text { Should correct waste disposal methods } \\
\text { be taught to the community? }\end{array}$ & Yes & $114(95.0)$ \\
\hline $\begin{array}{l}\text { Do you want to use less of disposable } \\
\text { item } \& \text { more of reusable items to reduce } \\
\text { waste generation? }\end{array}$ & Yes & $105(87.5)$ \\
\hline $\begin{array}{l}\text { Do you feel that less waste should be } \\
\text { generated by house hold for betterment } \\
\text { of environment? }\end{array}$ & Yes & $101(84.1)$ \\
\hline $\begin{array}{l}\text { Do you think that proper solid waste } \\
\text { removal \& disposal is important? }\end{array}$ & Yes & $107(89.1)$ \\
\hline
\end{tabular}

Table 4: M ethod of waste disposal by households

\begin{tabular}{|l|c|c|c|c|}
\hline $\begin{array}{l}\text { Type of } \\
\text { waste }\end{array}$ & $\begin{array}{c}\text { Feed animals } \\
\text { Number (\%) }\end{array}$ & $\begin{array}{c}\text { Burn } \\
\text { Number (\%) }\end{array}$ & $\begin{array}{c}\text { Dispose } \\
\text { in dustbin } \\
\text { Number (\%) }\end{array}$ & $\begin{array}{c}\text { Scrap } \\
\text { Number (\%) }\end{array}$ \\
\hline Food & $120(100.0 \%)$ & - & - & - \\
\hline Paper & - & $119(99.1 \%)$ & $1(0.9 \%)$ & - \\
\hline Plastic & - & $68(56.6 \%)$ & $52(43.4 \%)$ & - \\
\hline Metal & - & - & $20(16.6 \%)$ & $100(83.4 \%)$ \\
\hline Glass & - & - & $120(100.0 \%)$ & - \\
\hline
\end{tabular}
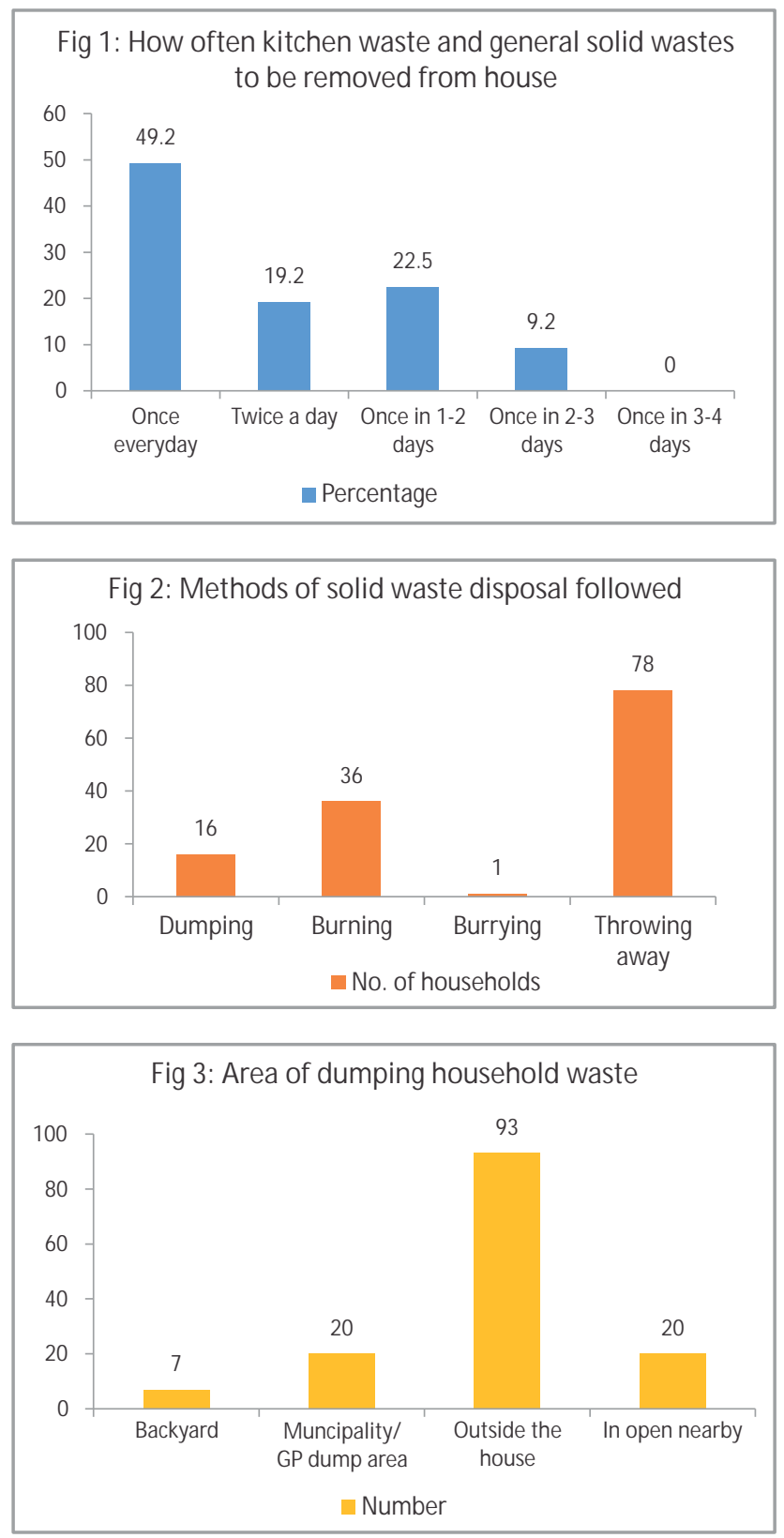

\section{Discussion}

In our study about $42.5 \%$ of the respondents were unskilled workers and $65 \%$ had studied upto primary class and $21.7 \%$ were illiterate. In a similar study done by Kumar 
$M$ et $\mathrm{al}^{6}$ in Bangalore it was found that $38.3 \%$ had studied upto secondary school, $28.0 \%$ had studied upto primary school and $4.0 \%$ were illiterate. In our study about $26.7 \%$ households had a total of less than 5 family members, 81 (67.5\%) had 5-10 family members and 7 (5.8\%) had more than 10 family members. In the study conducted by Kumar $\mathrm{M}$ et $\mathrm{al}^{6}$ it was found that $0.5 \%$ had more than 11 people, 2.0\% had 8-10 people, $7.7 \%$ had 5-7 people, $49.0 \%$ had 3-4 people, $32.0 \%$ had $1-2$ individuals and 8.85 had only one individual. In our study according to modified BG Prasad classification (2014) majority ie about 107 (89.2\%) families belonged to class V socio-economic strata, about 10 (8.3\%) belonged to class IV socio-economic strata, 2 (1.7\%) families belonged to class III socio-economic strata and $1(0.8 \%)$ belonged to class II socio-economic strata. Kumar M et $\mathrm{al}^{6}$ in their study found that $34.0 \%$ belonged to low income level, $42.0 \%$ belonged to middle income level and $24.0 \%$ belonged to high income level.

In the present study the subjects had a good knowledge about what is solid waste. $29.2 \%$ also knew about recycling of wastes. In a study conducted by Arora Let al ${ }^{7}$ it was found that $162(54 \%)$ of the respondents could be classified as possessing low knowledge, whilst $138(46 \%)$ respondents were having medium level of knowledge regarding waste management. It was found that in the study by Kumar $M$ et al $^{6}$ only $14.2 \%$ were aware about solid waste generation and $5.5 \%$ had knowledge of recycling of wastes. A study by Tatlonghari RV et al ${ }^{8}$ in Philippines showed that majority of the respondents knew segregation (55\%), and reuse and recycling (51\%). Study by Tatlonghari RV et $\left.a\right|^{8}$ revealed among the various media available for use within the community, local cable channel was the most widely preferred medium of solid waste management information. In the present study it was observed that neighbours for $20(16.7 \%)$, friends for $15(12.5 \%)$, newspapers for 15 (12.5\%) of respondents were the major source of information about solid waste management. Study by Kumar $M$ et $\mathrm{al}^{6}$ showed that municipality (3.2\%), friends and neighbours (1.0\%), media (4.5\%) and NGO's (5.8\%) were the major source of information. Tatlonghari RV et $\mathrm{al}^{8}$ in their study found that among the various media available for use within the community, local cable channel was the most widely preferred medium of SWM information. A study by Banga $\mathrm{M}^{9}$ in Zambia showed that when asked from whom they got their information on waste segregation, $39 \%$ of the households that had heard of solid waste segregation said they had learnt about it from friends and relatives, 30\% from the itinerant buyers, $27 \%$ from newspapers and magazines and $4 \%$ said they had learnt about it at school.

In our study about $90.8 \%$ felt that they play an important role in solid waste management. Results are similar to a study conducted by Ambat $\mathrm{B}^{10}$ where it was found that $88 \%$ of people reported that they too have a major role to play in solid waste management as they form the first part of solid waste management program as the generators of waste. They reported that even though there are very few initiatives from various organisations in waste collection and management but they are not successful. In the study conducted by Tatlonghari RV et $\mathrm{al}^{8}$ majority of the respondents realized their contributory role to the Solid waste management problem, taking into consideration the internal factor first before laying the blame on external factors. For this study, this attitude was rated as favorable since if people realized that problems were caused by themselves, then they would also realize that they could do something to solve the problems.

In the present study it was found that households generated $1-2 \mathrm{~kg}$ of solid wastes per day. Results are consistent with the study conducted by Ambat $\mathrm{B}^{10}$ where household waste was $1.5-2 \mathrm{~kg} /$ house in corporation, municipality and panchayath areas. Dumping, burying, burning and throwing away were some of the methods of waste disposal in our study. In the study by Ambat $B^{10}$ it was found that above $60 \%$ of the households simply throw away solid wastes outside the house. About $55 \%$ of households reduce, reuse and recycle waste materials. A study conducted by et al in Mogadishu showed that bury (27\%), burn (34\%) and dump (27\%) were the major methods of solid waste disposal. 


\section{Conclusion}

Solid waste management would remain to be the most urgent concern and task of urbanizing towns. The challenge confronting the City and many other booming towns in the country was the balance between environment and development. Toward this end, communication strategies toward environmental protection becomes crucial. Particularly in Solid waste management, turning intention to desirable behavior and creating favourable social and political environments should not only be the concern of local officials but also of residents.

\section{Recommedations}

We recommend that strict supervision and surveillance of refuse management activities.

- To achieve the goal of safe refuse management practices in household waste, awareness, education and importance of safe refuse disposal program should be initiated for the public.

- Refuse disposal laws either by local government or Ministry of Environment should ensure that the safe refuse management is embarked upon and refuse should not be discarded in the rivers, gutters, drains, open space or public locations like parks, buildings or streets.

- Laws should be publicized on safe refuse disposal method; this should be adequately promoted and advertised.

- Government should encourage private/government partnership in wastes management at an affordable rate. It is very important that the related professionals such as the sanitary inspectors become involved as they play a vitalrole in promoting awareness on proper refuse management.

\section{What one can do to reduce solid waste?}

1. Carry owncloth or jute bag when one goes shopping
2. Say no to all plastic bags as far as possible

3. Reduce the use of paper bags also.

4. Reuse the soft drinks poly bottles for storing water.

5. Segregate biodegradable and the non-biodegradable are put into separate bins and disposed off separately.

6. Dig a compost pit in one's garden and put all the biodegradable materialsinto it.

7. See to it that all garbage is thrown into the municipal/Panchayat bins as the collection is generally done from there.

8. When one goes out, not throw paper and other wrappings or even leftover food here and there, make sure that it is put in the correct place, or into a dustbin.

\section{What one should not do?}

1. Do not litter. If one drops litter, it will encourage others to litter.

2. Do not put out garbage too early, especially garbage that contains meat and fish scraps.

3. Do not dump or litter illegally at the sides of the roads or in gullies, it is not only unsightly but dangerous and hazardous to health.

4. Do not allow water to collect in the garbage bin.

5. Do not place old stoves, refrigerators, or other big or bulky items at the side of the road.

6. Do not use an oversize bin (e.g. 50 gallons (190L) drum) to contain the garbage. They are generally too heavy to lift.

7. Do not overload the garbage bags; they may burst as a result of excessive weight or bulk.

8. Do not throw broken objects (e.g. glass, ceramic, etc.) into the garbage without wrapping them first.

9. Do not place needles and syringes in the garbage or leave them lying around.

10.Do not overload the waste bin or put out loosely tied or untied bagsfor collection.

11.Do not compact waste in the waste bin. This makes it difficult to extract the waste. 


\section{References}

1. Femi $F$, Oluwole O. Management of municipal solid wastes. Academia.edu [updated july 2013; cited july 2013]. Available fromhttp:// www.academia.edu/4254191/M anagement_of_M unicipal_S olid_Waste (accessed on 30-03-2015)

2. United Nations Environment Programme International Source Book on Environmentally Sound Technologies (ESTs) for Municipal Solid Waste Management (MSWM). Available from- http://www.unep.or .jp/ietc/ ESTdir/Pub/M SW/index.asp (accessed on 30-03-2015)

3. Mukherjee S. The science of clays: Applications in industry, engineering and environment; 2013.

4. Anand S. Solid waste managent. M ittal Publication; 2010.

5. Solid Waste Management Principles and Terminologies. Prakriti, Centre for Management Studies, Dibrugarh University as part of the National Environment Awareness Campaign, 2006 - 07 for distribution. Available in - http://cmsdu.org (accessed on 30-03-2015)

6. Kumar M, Nandini N. Community attitude, perception and willingness towards solid waste management in Bangalore city, Karnataka, India.
International Journal Of Environmental Sciences 2013; 4 (1): 87-95

7. Arora L, Agarwal S. Knowledge, Attitude and Practices regarding Waste Management in Selected Hostel Students of University of Rajasthan, Jaipur. International Journal of Chemical, Environmental and Pharmaceutical Research 2011;2(1): 40-43

8. Tatlonghari RV, Jamias SB. Village-Level Knowledge, Attitudes and Practices on Solid Waste Management in Sta. Rosa City, Laguna, Philippines. Journal of Environmental Science and M anagement 2010; 13(1):35-51

9. Banga M. Household Knowledge, Attitudes and Practices in Solid Waste Segregation and Recycling: The Case of Urban Kampala. Zambia Social Science J ournal 2011; 2 (1): 27-39

10. Ambat B. Study of the attitude and perception of community towards solid waste management - a case study of Thiruvananthapuram city phase ii. Kerala research programme on local level development 2003.

11. M waura P, Owillah EO, Dahir M. Report of KAP survey on solid waste management in M ogadishu, Somalia. UN HABITAT 2012. 